LRAD-Based Airflow Monitors

Los Alamos

NATIONAL LABORATORY

Los Alamos National Laboralory is operated by the University of Califormin for the United States Dipartmint of Encryy under contract W-74(1).5-ENG-.36. 
Edited by Gerry Edwards, Group IS-1

Composition and Layout by AnnMarie Dyson, Group IS-1

Illustrations by AnnMarie Dyson, Group IS-1

An Affirmative Action/Equal Opportunity Employer

This report ans prepard as an account of work sponsored by an agency of the United States Government. Neither The Regents of the University of California, the United States Government nor any agency thereof, nor any of the ir e'mploye's, makes any warranty, express or implied, or assumes any legal liability or responsibility for the accuracy, completeness, or usefulness of any imformation, apparatus, product, or process disclosed, or represents that its use would not infringe prizately owned rights. Reference herein to amy specific commercial product, process, or service by trade name', trademark, manufucturer, or otheraitsi, doe's not necessarily constitute or imply its endorsement, recommendation, or faroring by The Regents

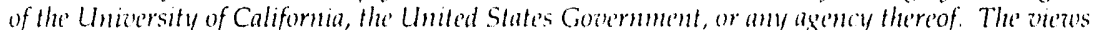
and opintons of antinors expressed herein do not nectsisurly state or reflect those' of The Re'gents of the Unizersity of Califormia, the United States Government, or any agency thereof. 
LRAD-Based Airflow Monitors

R. W. Caress

D. W. MacArthur

K. S. Allander

J. A. Bounds

M. M. Catlett

S. E. Garner

J. D. Johnson

J. P. Johnson

D. A. Rutherford 


\title{
LRAD-BASED AIRFLOW MONITORS
}

\author{
by
}

\author{
R. W. Caress, D. W. MacArthur, K. S. Allander, J. A. Bounds, \\ M. M. Catlett, S. E. Garner, J. D. Johnson, J. P. Johnson, and D. A. Rutherford
}

\begin{abstract}
Conventional alpha detectors depend upon detecting the alpha particle directly. This is often difficult because typical alpha particles generated by uranium or plutonium travel less than $3 \mathrm{~cm}$ in air. In contrast, the long-range alpha detector (LRAD) technology relies on detecting the ions generated by alpha particles as they lose their energy in air, rather than detecting the alpha particles themselves. We have designed, built, and used LRAD-based airflow monitors to detect alpha contamination. The airflow monitor is composed of a sample chamber with air and ion filters at one end and an ion detector at the opposite end. A set of small fans is located just outside the ion detector to provide an airflow that transports the ions into the ion detector. Ambient air enters through the particulate and ion filters, passes over and through an object located in the sample chamber, through the ion detector, then leaves the system through the fans. The number of ions present is proportional to the amount of contamination on the object's surface. This work describes the design, construction, and testing of the LRAD-based airflow monitors.
\end{abstract}

\section{INTRODUCTION}

All traditional alpha detectors operate by detecting the alpha particle directly. This is often complicated by the short range of alpha particles in air (a typical $5-\mathrm{MeV}$ alpha particle created by the decay of uranium or plutonium will only travel $\sim 3 \mathrm{~cm}$ in air). For the best monitoring results, traditional alpha monitors must therefore be held within a few centimeters of (or in contact with) the source of contamination. Traditional monitors have several inherent weaknesses:

- they can only detect contamination located directly beneath the probe (most probes have a surface area of only about $17 \mathrm{~cm}$ by $5 \mathrm{~cm}$ );

- they cannot satisfactorily monitor uneven surfaces; and

- they cannot reliably achieve the sensitivity levels demanded by Department of Energy (DOE) and Environmental Protection Agency (EPA) regulations. 
In contrast with all other alpha detectors, monitors based on the long-range alpha detector (LRAD) technology $1-8$ detect the ions created by alpha particles as they travel through the air, rather than the alpha particles themselves. An alpha particle loses energy in air mainly by creating electron/positive ion pairs. The electron instantly attaches itself to a neutral ion, creating a negative ion. With each ion pair produced in air, an alpha particle loses about $35 \mathrm{eV}$; therefore, a typical $5-\mathrm{MeV}$ alpha particle will produce about $150,(0) 0$ ion pairs. In an LRAD, these ions can be transported for several meters ${ }^{4}$ before being detecied in an ion detector. The primary difference between the airflow and the fanless monitors is in the manner in which ions are transported: in an airflow monitor, the ions are transported by an air current; in a fanless monitor, they are transported by an electric field. This report centers on the airflow monitoring system. More information on the fanless LRAD system may be found in Refs. 7-12.

The airflow monitor is composed of a sample chamber with air and ion filters at one end and an ion detector at the opposite end. A set of small fans is located just outside the ion detector to provide an airflow that transports the ions into the ion detector (see Fig. 1). Ambient air enters through the particulate and ion filters, passes over and through an object located in the sanple chamber, through the ion detector, then leaves the system through the fans. The number of ions present is proportional to the amount of contamination on the object's surface. If a contaminated object is placed in the sample chamber is alpha contaminated, the ions created near its surface will be transported by the air current to the ion detector. Either positive or negative ions can be collected creating a small ( fA) current that can be measured with a sensitive electrometer. The current from this ion detector is proportional to the number of ions in the chamber which, in turn, is proportional to the amount of alpha contamination on the surface of the object.

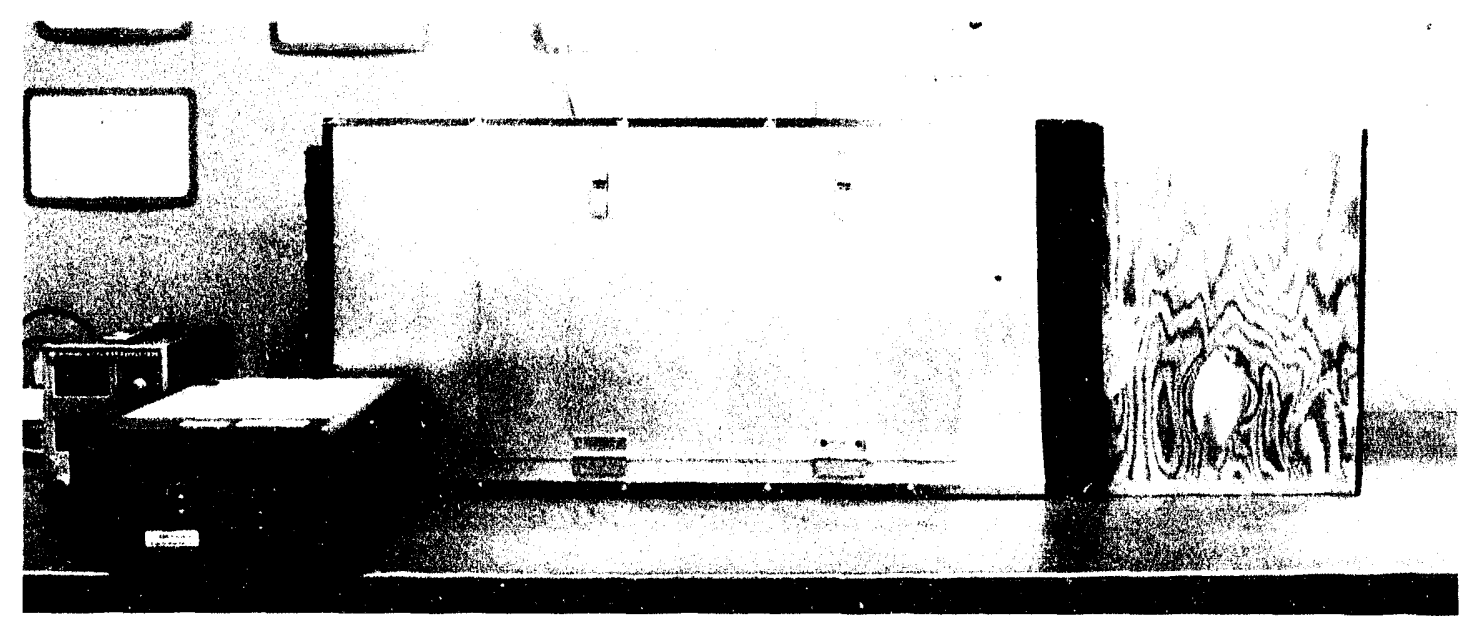

Figure 1. LRAD-based object monitor.

A major problem for traditional alpha monitors is monitoring contaminated objects (surh as equipment or tools) that have unusually shaped or non-uniform surfaces, because contamination can be located in places that are difficult to reach with a probe. An airflow monitor probes with an air current and can, therefore, measure in any space where air can penetrate.

Although the LRAD is primarily an alpha detector, any ions created in the sample chamber will be detected. Therefore, an LRAD is also sensitive to beta, gamma, and neutron radiation. However, in reasonably sized monitors, beta and gamma particles deposit most of 
their energy in the walls of the chamber rather than in the air (neutrons interact weakly in the LRAD and, hence, do not create a large signal in the detector). In most cases, the contribution from other radiation is negligible compared to the contribution from alpha particles.

\section{BACKGROUND}

Early LRAD devices were similar to the small monitor shown in Fig. 2. These contained a fan for transporting ions through the air; the ion detector (lower left); the sample chamber (center); and the ion filter (inside the pipe on the right). Although no air filter was present in the early LRAD, the ion filter was constructed in a long pipe to provide isolation from external air currents. A second pipe connecting the sample chamber to the ion detector ensured that the detected ions were created by alpha particles in the sample chamber and not by alpha particles directly penetrating the ion detector. Because the length of the pipe exceeds the range of an alpha particle in air, alpha particles were prevented from directly entering the ion detector itself.

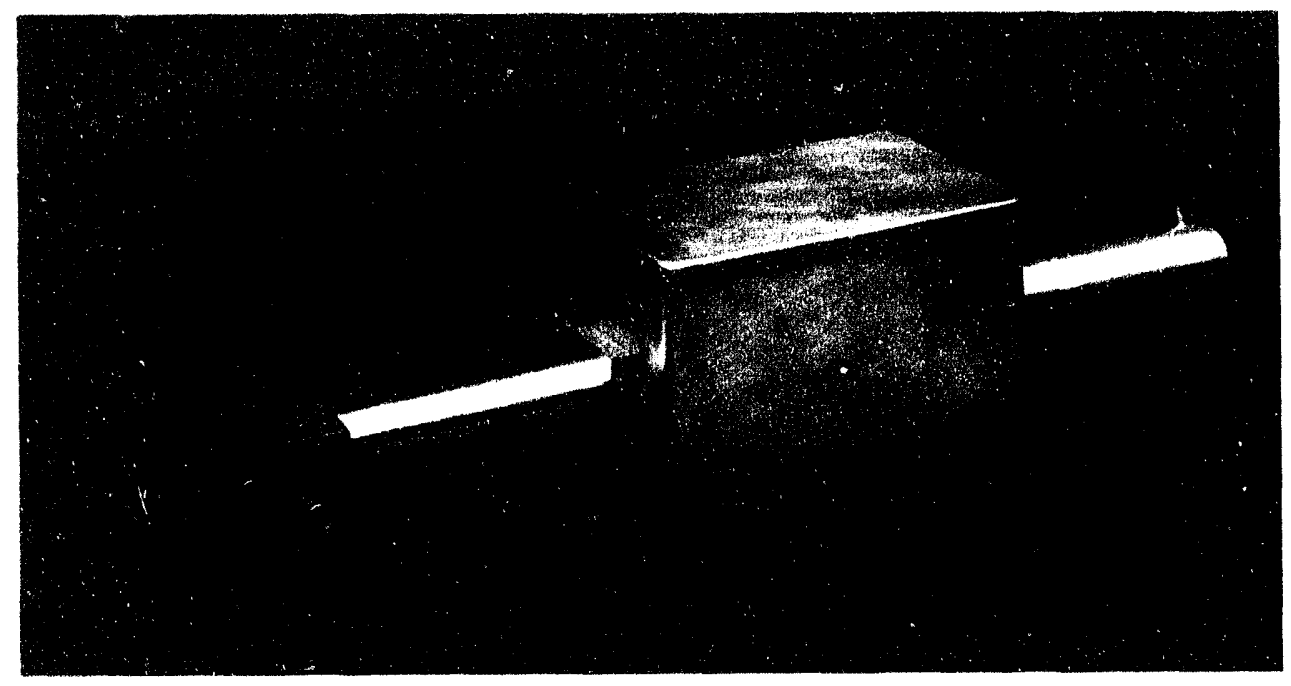

Fig. 2. Prototype LRAD containing a fan for transporting ions through the air; the ion detector (lower left), the sample chamber (center), and the ion filter (inside the pipe on the right).

Several large LRAD-based airflow monitors, similar to the one shown in Fig. 1, have been built and are in use at Los Alamos National Laboratory's (LANL) Advanced Nuclear Technology Group (N-2) and other locations in and outside LANL. Eberline Instrument Corp. is manufacturing the large LRAD-based airflow monitors (see Fig. 3) for commercial distribution. 


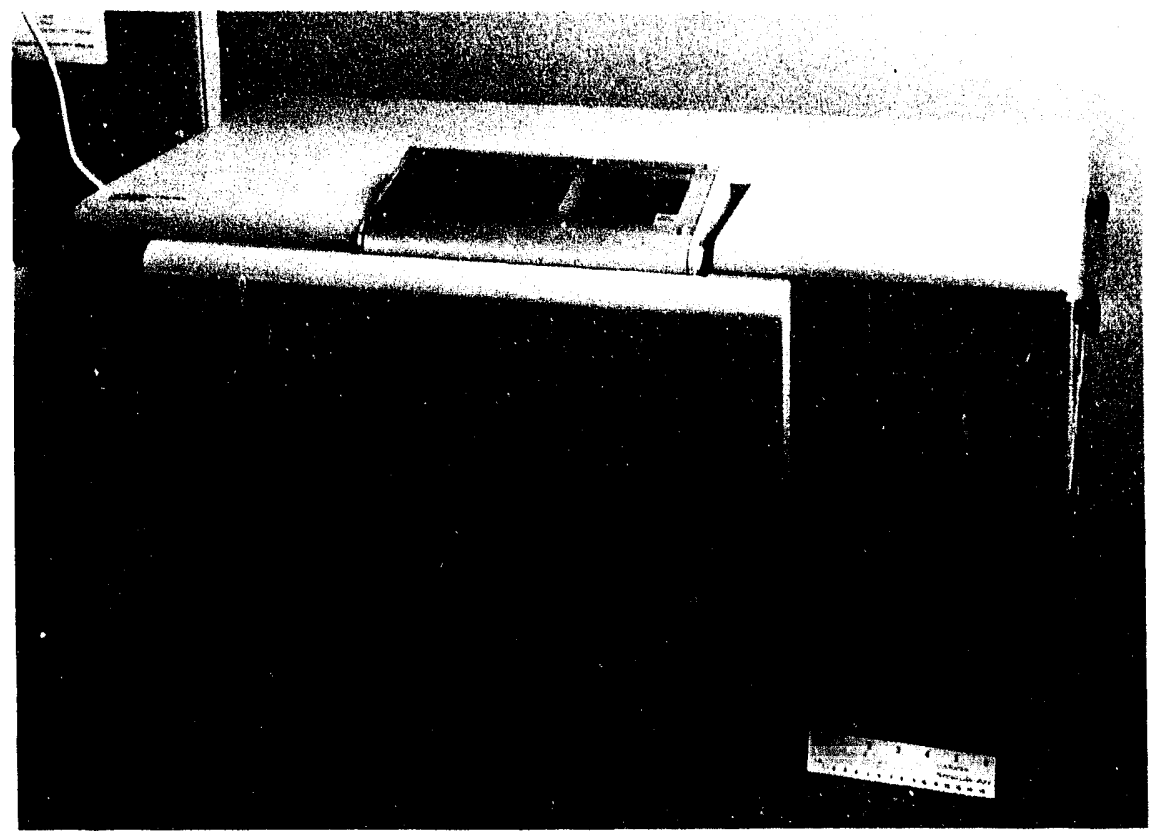

Figure 3. Eberline Object Monitor.

\section{LARGE AIRFLOW MONITOR DESIGN}

The large airflow monitor (see Fig. 4) consists of a sample chamber $(40 \mathrm{~cm}$ high by $60 \mathrm{~cm}$ wide by $60 \mathrm{~cm}$ long) separating a filter located at one end from an ion detector and a fan bank located at the opposite end. The exterior dimensions of the complete large airflow monitor (including the air filter, the electrostatic filter, the ion detector, and the fan manifold) are $\sim 40$ by 60 by $110 \mathrm{~cm}$.

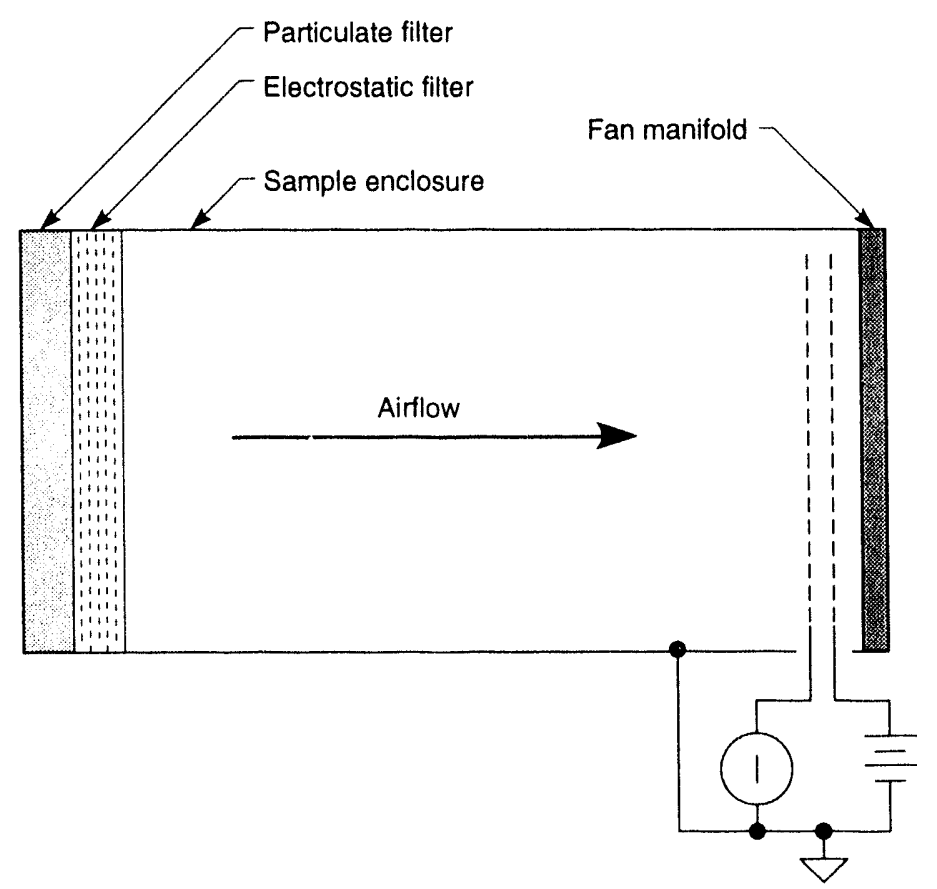

Figure 4. LRAD linear source response. 
The fan manifold consists of 24 small (brushless, dc, variable speed) fans that pull air through a filter system into the detector. A particulate filter removes dust and dirt particles from the air, and, more importantly, it ensures a uniform airflow through the sample chamber and reduces the influence of outside air currents on the detector. Without this filter, even a minor airflow disturbance can alter the current readings significantly. After passing through the particulate filter, the air travels through an electrostatic filter that removes any ions already present in the ambient air. Removing these ions ensures that the ions detected by the LRAD originated inside the sample chamber. For these tests, the electrostatic filter was a wire mesh (brass) screen (held at $300 \mathrm{~V}$ ) positioned between two similar grounded screens. Any ions entering the ion filter will be attracted to either one screen or the other and will not be allowed to enter the sample chamber.

The filtered air then flows over and/or through the object to be monitored. If the object is contaminated with an alpha emitter, ions created near the object's surface by the alpha particles will be transported by the airflow to the ion detector. While the basic design of the airflow monitor remained the same in every experiment, many detector components (such as the ion detector) were altered and the results tabulated.

\section{EXPERIMENTS AND RESULTS}

Experiments conducted with the large LRAD-based object monitor were intended to maximize the efficiency of the detector, to minimize the background noise of the detector, and to improve upon the basic mechanical design.

\section{A. Source Linearity}

Each LRAD is tested to verify that the detector response to a set of calibrated ${ }^{239} \mathrm{Pu}$ alpha sources is linear. Figure 5 shows results for a large LRAD-based object monitor; here, the linearity is shown using alpha source strengths varying from 100 to $1100 \mathrm{dpm}$. Data was taken with each strength source for 10-15 min with 5-min periods of background in between. Sources with activities of $210 \mathrm{dpm}$ and above are clearly detectable above background. Using an airflow monitor with a higher detection efficiency and better signal-to-noise ratio $(\mathrm{S} / \mathrm{N})$, even sources smaller than $100 \mathrm{dpm}$ are clearly visible.

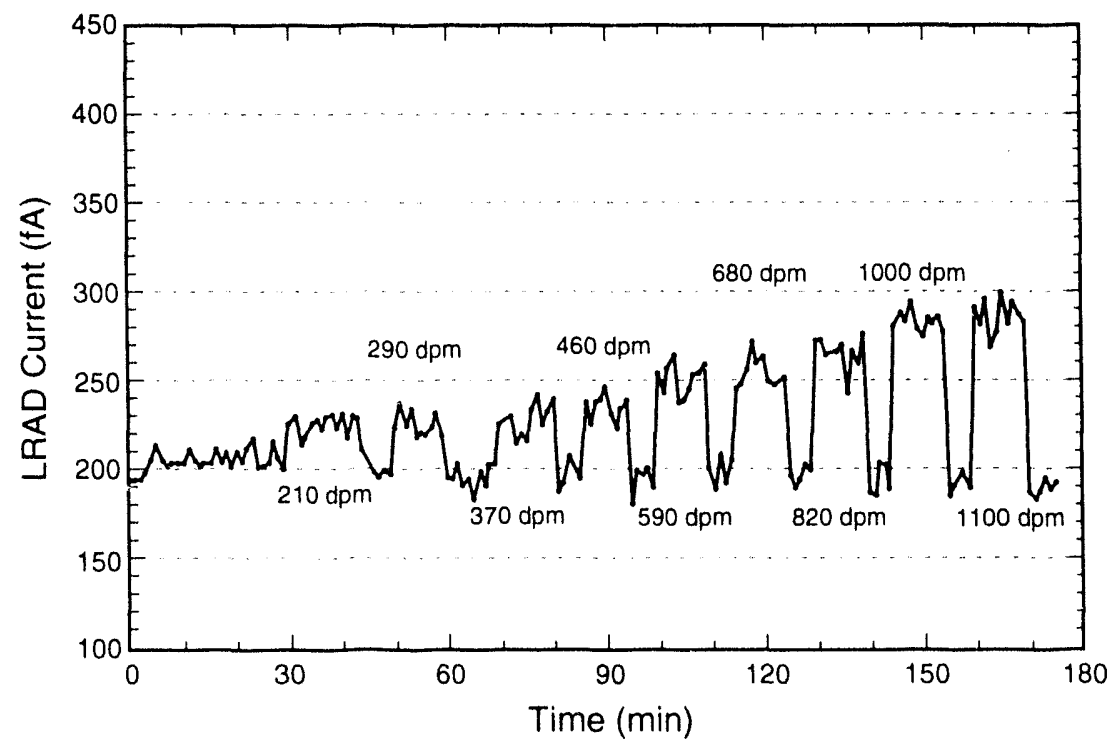

Figure 5. LRAD linear source response. 


\section{B. Airflow Velocity and Ion Detector Voltage Optimization}

In the standard configuration, the ion detector comprises two wire grids, or screens, about $1 \mathrm{~cm}$ apart: a signal grid, at virtual ground potential; and a high-voltage (HV) grid, held at positive voltage. When the ions move between the two grids, they are attracted either to the signal grid or to the HV grid. The ions collected on the signal grid create a small (10)-10() fA) current that is measured by a sensitive electrometer. The measured current is proportional to the number of ions in the sample chamber, which, in turn, is proportional to the amount of contamination on the object. The detector works equally well with either polarity of HV; the decision to apply positive HV (collect negative ions) is arbitrary. ${ }^{4}$ Commercial LRADbased airflow monitors will have a high-efficiency particulate air (HEPA) filter placed between the ion detector and the fan manifold to keep the contamination from being released to the outside air.

Airflow velocity and ion detector voltage were optimized by measuring the source response as a function of (1) the voltage to the fans (and thus the airflow velocity through the sample chamber); (2) the voltage applied to the ion detector; and (3) the source position inside the sample chamber. A $2.2 \times 10^{5}-\mathrm{dpm}, 238 \mathrm{Pu}$ source was used for these tests. Three source positions were chosen: $10 \mathrm{~cm}$ from the signal grid, in the center of the chamber (3) $\mathrm{cm}$ from the signal grid), and $50 \mathrm{~cm}$ from the signal grid $(10 \mathrm{~cm}$ from the electrostatic filter). Figure 6 shows the results divided into three groups: from 0 to $105 \mathrm{~min}$, the source was $10 \mathrm{~cm}$ from the signal grid; from 105 to $205 \mathrm{~min}$, the source was in the center of the chamber; and from 205 to $309 \mathrm{~min}$, the source was $50 \mathrm{~cm}$ from the signal grid. A short background measurement was taken before taking data in each of these positions.

For each of the source positions (see Fig. 6), we tested three airflow velocities and three ion detector voltages. These measurements can be seen in the levels shown for each position. Three levels represent the three different airflow velocities: $<15 \mathrm{fpm}, 18 \mathrm{fpm}$, and $35 \mathrm{fpm}$, as illustrated in the central source position of Fig. 6. For each of these three airflow velocities, there are three levels representing three ion detector voltages: $45 \mathrm{~V}, 90 \mathrm{~V}$, and $135 \mathrm{~V}$, as illustrated for the source position $10 \mathrm{~cm}$ from the signal grid. The same airflow velocity and ion-detector voltage-level patterns apply to all three source positions.

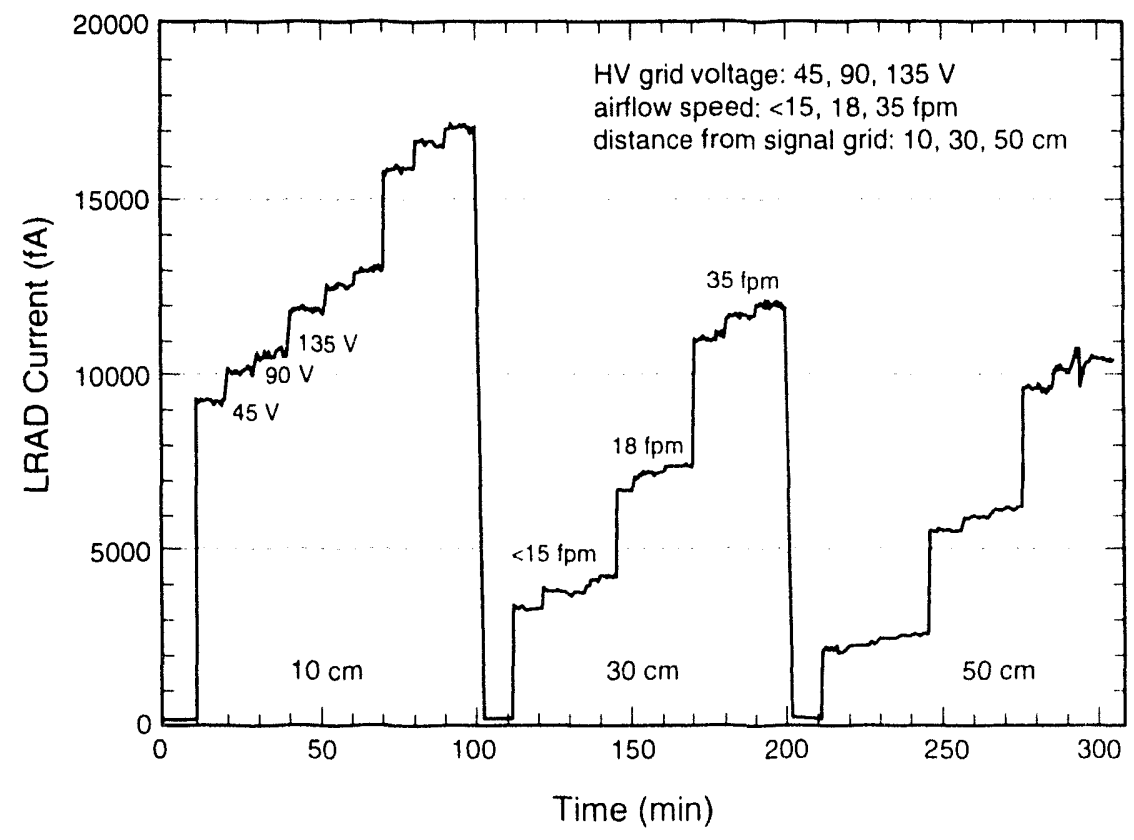

Figure 6. Airflow velocity and $H V$ grid voltage. 
The data in Fig. 6 shows the signal is strongest when the source is closest to the signal grid, the airflow velocity through the sample chamber is fastest, or the voltage on the ion detector is largest. To maintain consistency throughout our tests, the object to be monitored is always placed in the center of the chamber. The largest signal is obtained with an airflow velocity of $35 \mathrm{fpm}$ and the ion detector at $1.35 \mathrm{~V}$. However, to detect with maximum sensitivity, the $\mathrm{S} / \mathrm{N}$ must be maximized rather than the signal itself. As either airflow velocity or the voltage on the ion detector is increased, the noise as well as the signal will increase. Thus, the maximum $\mathrm{S} / \mathrm{N}$ does not necessarily correspond to the maximum signal. The $S / N$ ratios for a number of ion detector and fan voltages are presented in Table I. Our anemometer will not reliably read below $15 \mathrm{fpm}$, thus, any lower airflow velocities can only be approximated as $<15 \mathrm{fpm}$.

The largest $\mathrm{S} / \mathrm{N}$ is generated with an ion detector voltage of $+45 \mathrm{~V}$ and the lowest airflow velocity. At present, the LRAD-based airflow monitors operate with a $15-\mathrm{V}$ fan voltage, corresponding to an airflow velocity of $18 \mathrm{fpm}$. To obtain the lowest possible noise level, we would like to operate the detector with a lower airflow velocity; however, the fans currently in use are not rated for operation below $+14 \mathrm{~V}$. We are investigating the possibility of using other fans to further reduce the airflow.

Table I. Signal-to-noise ratios $(\mathrm{S} / \mathrm{N})$ for an $1100-\mathrm{dpm}$ source.

\begin{tabular}{|c|c|}
\hline $\begin{array}{c}\text { HV grid voltage (V) } \\
(\mathbf{1 5 - V} \text { fan voltage) }\end{array}$ & S/N A verage (fA) \\
\hline 45 & 97 \\
\hline 90 & 92 \\
\hline 180 & 84 \\
\hline $\begin{array}{c}\text { Airflow speed (fpm) } \\
\text { (90-V, HV grid voltage) }\end{array}$ & S/N Average (fA) \\
\hline 1 & 111 \\
\hline 18 & 96 \\
\hline 35 & 73 \\
\hline
\end{tabular}

\section{LRAD Ion Detector Design}

We tested three different ion detector designs in the large airflow monitor. The sensitive elements of these detectors were (1) two pieces of screening perpendicular to the direction of airflow, (2) two sets of copper plates oriented parallel to the direction of airflow, and (3) two copper plates with holes drilled through them also perpendicular to the direction of airflow

1. Perpendicular Screens. In the initial design of the ion detector wire mesh screening (held in place by Teflon standoffs) was used for signal and HV electrodes. However, this design was labor intensive to build, the screens were subject to warping, and their attachment in the standoffs was somewhat precarious. This structure was described in detail in Sec. IV. B; the results are detailed in Figs. 5 and 6 and Table I.

2. Parallel Plates. The parallel plate system was designed to collect both polarities of ions (instead of just one) in an attempt to make the detector more efficient. This system was 
also easier to build and more rugged. Figure 7 shows a schematic of the parallel plate system, which consists of a stack of horizontal copper plates. Consecutive plates are connected to alternate terminals of a $45-\mathrm{V}$ battery, so that every other plate is at the same potential. The electrometer reads the current between the oppositely charged sets of plates, which represents the sum of the positive and negative ions present in the sample chamber. Each plate measures $8 \mathrm{~cm}$ by $48 \mathrm{~cm}$ and is separated from its closest neighboring plate by $1.5 \mathrm{~cm}$; the plate sets are isolated from the sample chamber with Lexan* standoffs.

As in the earlier tests, the detector source response was measured at three positions $(10 \mathrm{~cm}$, center, and $50 \mathrm{~cm}$, respectively, from the ion detector). The percentage of ions captured (and thus a measure of the efficiency of the detector) is obtained by dividing the current measured by the LRAD by the theoretical current expected from the source. These results are shown in Fig. 8, along with the wire-screen ion-detector efficiency obtained with the data from Fig. 6. As expected, since the parallel plates collect both ion charges, their efficiency was higher than that of the wire screens. However, the parallel plates exhibited more noise than the wire screens, and the plates' efficiency dropped off with time. The noise could probably have been reduced by further cleaning of the pieces during assembly.

Furthermore, the plates were supported by a pressure fit to the top and bottom of the large airflow monitor, and we have observed that stressing any component can significantly increase noise in the system. We believe the loss of efficiency is due to the plates drifting to a non-zero potential relative to the sample chamber. The plates were isolated from the chamber and, therefore, not grounded relative to it. If the plates do not collect equal numbers of positive and negative charges, one polarity of charges will build up, causing fringe fields to the chamber and, ultimately, causing ions to be lost.

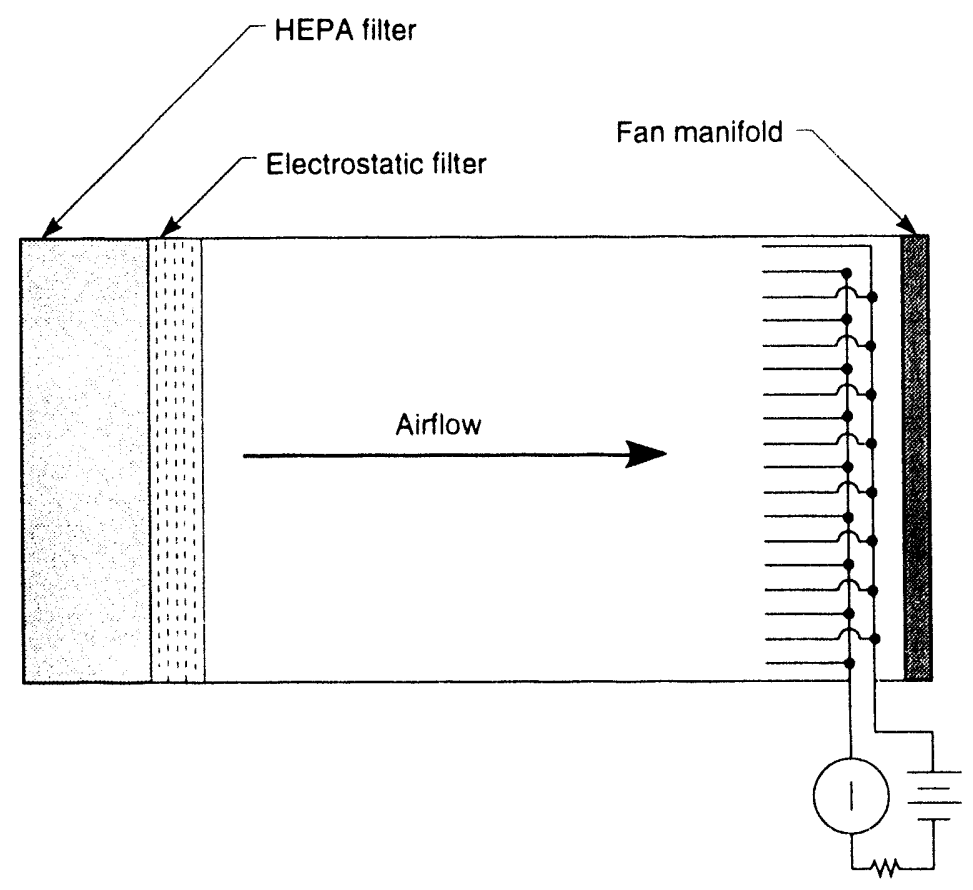

Figure 7. Parallel plate schematic.

We expect that the parallel-plate approach will continue to offer higher efficiency at the cost of the extra weight of the plates (about $9 \mathrm{~kg}$ ). Although the heavy copper plates create a more sturdy detector, they make the system virtually non-portable. 


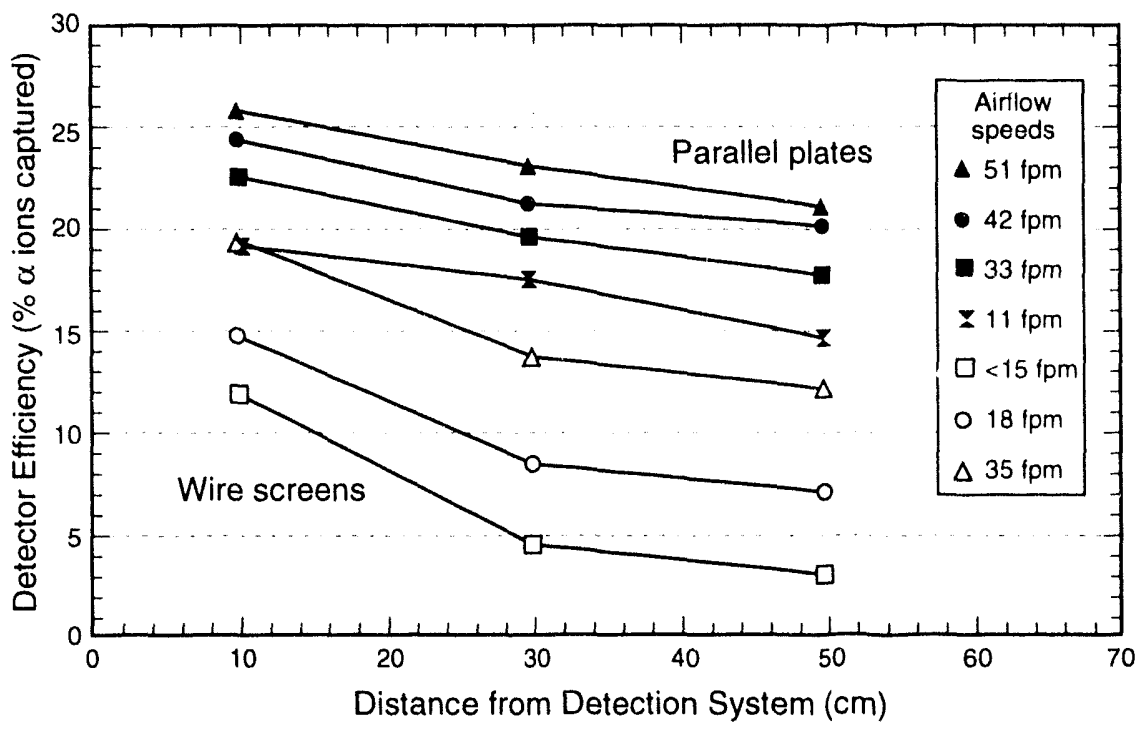

Figure 8. Efficiency of parellel plates vs wire screens.

3. Drilled Plates. We designed a detector using a set of drilled copper plates in place of the wire screens. This detector was easier to assemble and much sturdier than the wire screen system, yet not as complex as the parallel plate system. The new HV and signal plates were $0.16 \mathrm{~cm}$ by $50 \mathrm{~cm}$ by $35 \mathrm{~cm}$, with $0.64-\mathrm{cm}$-diam holes drilled through them in a $0.95-\mathrm{cm}$ staggered pattern, as shown in Fig. 9 . A $1.3-\mathrm{cm}$ border was left intact around the perimeter of each plate for rigidity. By comparison, the new system is quieter and shows greater source response than the brass screen detectors, and all new LRAD systems are built with drilled-plate ion detectors.

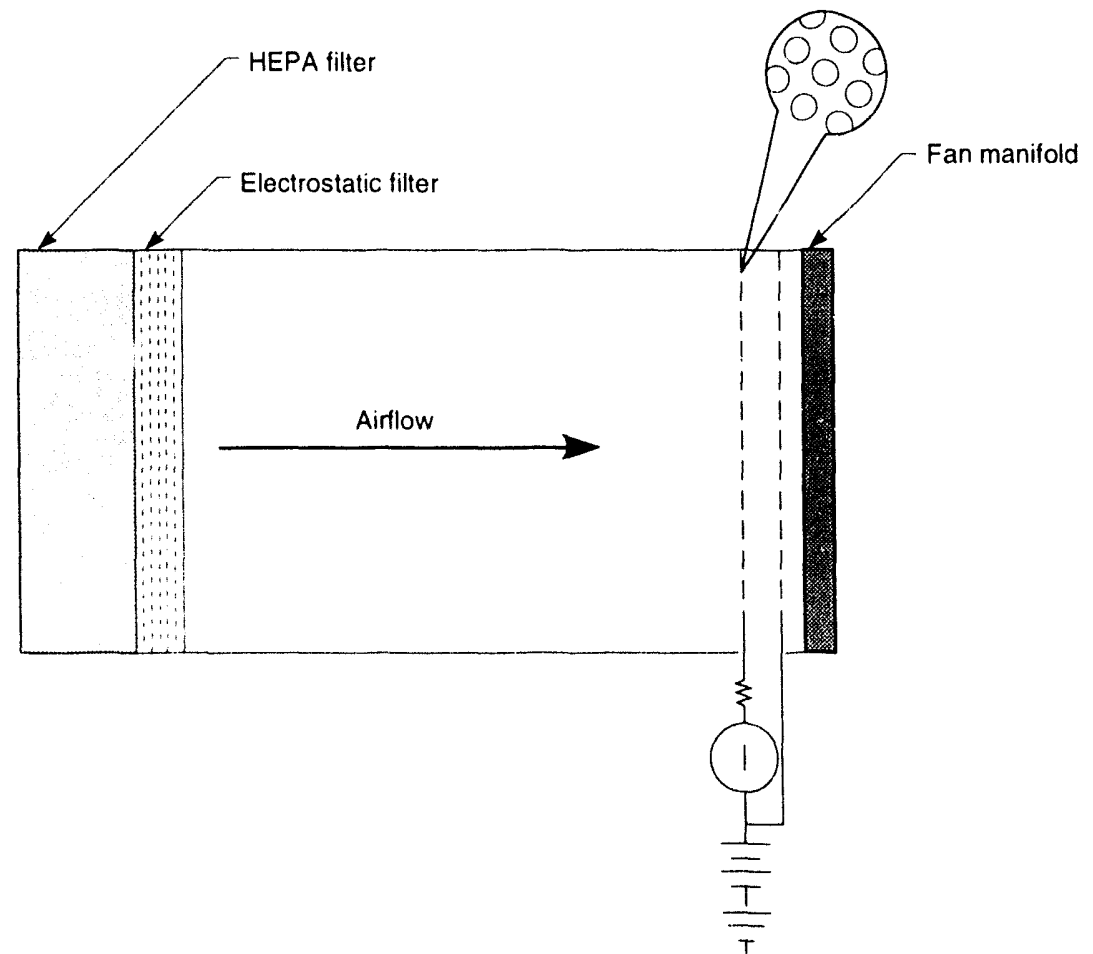

Figure 9. Drilled copper plate schematic. 


\section{Filter Optimization}

We compared six different particulate filters for the LRAD. Three thicknesses of furnace filter were compared with a HEPA filter, and the results are shown in Table II. Both background and source response were tested with three different airflow velocities. Although the furnace filters seem to be working well, they may not keep the airflow uniform throughout the chamber. A person walking past the detector can cause the current readings to fluctuate severely.

Table II. Detector current as a function of filter type and air velocity.

\begin{tabular}{|c|c|c|c|}
\hline \multirow[b]{2}{*}{ Measureinent } & \multicolumn{3}{|l|}{ Air Velocity } \\
\hline & $15 \mathrm{fpm}$ & $20 \mathrm{fpm}$ & $25 \mathrm{fpm}$ \\
\hline \multicolumn{4}{|l|}{ Background: } \\
\hline 1 furnace filter & $165.7 \pm 4.4 \mathrm{fA}$ & $166.4 \pm 5.3 \mathrm{fA}$ & $166.1 \pm 9.1 \mathrm{fA}$ \\
\hline 3 furnace filters & $164.7 \pm 4.3 \mathrm{fA}$ & $165.0 \pm 4.9 \mathrm{fA}$ & $183.5 \pm 8.7 \mathrm{fA}$ \\
\hline 5 furnace filters & $149.9 \pm 5.8 \mathrm{fA}$ & $156.0 \pm 3.5 \mathrm{fA}$ & $156.6 \pm 7.1 \mathrm{fA}$ \\
\hline HEPA & $164.0 \pm 7.5 \mathrm{fA}$ & $164.4 \pm 12.3 \mathrm{fA}$ & $185.0 \pm 41.7 \mathrm{fA}$ \\
\hline \multicolumn{4}{|l|}{ w/550-dpm source: } \\
\hline 1 furnace filter & $215.7 \pm 4.4 \mathrm{fA}$ & $221.1 \pm 13.3 \mathrm{fA}$ & $221.4 \pm 6.1 \mathrm{fA}$ \\
\hline 3 furnace filters & $214.7 \pm 7.4 \mathrm{fA}$ & $224.0 \pm 11.5 \mathrm{fA}$ & $227.4 \pm 6.0 \mathrm{fA}$ \\
\hline 5 furnace filters & $209.4: \pm 7.5 \mathrm{fA}$ & $210.1 \pm 8.9 \mathrm{fA}$ & $212.1 \pm 4.8 \mathrm{fA}$ \\
\hline HEPA & $217.2 \pm 11.5 \mathrm{fA}$ & $223.5 \pm 9.6 \mathrm{fA}$ & 24() $.1 \pm 24.1 \mathrm{fA}$ \\
\hline \multicolumn{4}{|l|}{$\begin{array}{l}\text { Source uptake: } \\
\text { (source - background) }\end{array}$} \\
\hline 1 furnace filter & $50.0 \pm 8.4 \mathrm{fA}$ & $54.7 \pm 14.3 \mathrm{fA}$ & $55.3 \pm 10.9 \mathrm{fA}$ \\
\hline 3 furnace filters & $50.0 \pm 8.3 \mathrm{fA}$ & $59 .() \pm 12.9 \mathrm{fA}$ & $43.9 \pm 10.6 \mathrm{fA}$ \\
\hline 5 furnace filters & $59.5 \pm 9.5 \mathrm{fA}$ & $54.1 \pm 9.6 \mathrm{fA}$ & $55.3 \pm 8.6 \mathrm{fA}$ \\
\hline HEPA & $53.2 \mathrm{fA}$ & $59.1 \mathrm{fA}$ & $55.1 \mathrm{fA}$ \\
\hline
\end{tabular}

A particulate filter is currently used with the airflow monitors to remove particulates from the air before it enters the sample chamber. For use in contaminated environments, a HEPA filter will be necessary to filter the air after it leaves the LRAD. Although air particulates need to be removed prior to the sample chamber, this can be accomplished through less expensive and easier means than a HEPA filter. 


\section{APPLICATIONS}

Many potential applications exist for LRAD-based airflow monitors. In addition to the basic object monitors, many variations on the airlow monitor theme are possible, including pipe, tank, duct, and drum monitors, and more generally, personnel, environmental, and waste monitors.

\section{A. Object Monitors}

We are designing small, medium, and large LRAD-based airflow monitors to accommodate the widest possible range of applications. Each size detector has a variety of applications. For example, the small monitor could be used for monitoring dosimetry badges and other small items. The medium monitors could be used to monitor a large variety of things from nuclear instrumentation module bins and other electronic equipment to hammers and other tools. Large items such as computers or large pieces of equipment could be successfully monitored in the large monitor. The large monitor is in "production" mode and has been given to experimenters outside our immediate group and at other DOE facilities for use/testing purposes.

\section{B. Pipe and Duct, Tank, and Drum Monitors}

Monitoring for alpha sontamination inside pipe and duct systems generally means completely disrupting the system. The disruption can be minimized with LRAD technology. We have created an LRAD-based pipe monitor by putting a fan on one end of the pipe and an ion detector on the other end, making the pipe the sample chamber. In many cases, the pipe does not have to be removed from the system; as long as the airflow can penetrate the length of pipe, the disruption can be minimized. This idea can be applied to a number of things too large for our large object monitor, such as duct systems, tanks and drums. In many cases, this type of thorough monitoring is only possible with an LRAD since the surfaces that need monitoring are not accessible by conventional means.

\section{Personnel Monitors}

Another variation of the LRAD-based airflow monitor is the personnel monitor, which includes whole-body, hand and arm, and clothing monitors.

The whole-body monitor is a telephone-booth-shaped version of the large object monitor, with an air intake at the base and ion detector/fan manifold at the top. The individual would step into the sample enclosure upon leaving a radiological area. Ion-free air enters through the base of the monitor, and any contamination located on the person would be evidenced by the ions created in the clean air and detected by the ion detector at the top of the monitor.

The hand and arm monitor is largely the same design as the medium-sized object monitor, with holes cut into the side for the individual's arms to fit through. It will be necessary to provide a special sleeve around the arm openings to provide an air seal necessary for the operation of the LRAD.

\section{Environmental Monitors}

The environmental monitor is similar in design to the large object monitor, but optimized specifically for environmental applications. One environmental application of the airflow style monitor is the ambient-air-quality monitor (for radon concentrations and radioactive stack emissions). LRAD radon monitors offer a sensitive, real-time alternative to commercially available radon detectors, and stack emissions can be easily monitored will an LRAD design similar to the duct and pipe monitor. 


\section{E. Waste Monitors}

LRAD-based waste monitors have applications for both solid and liquid waste; however, airflow style monitors will probably only be used for solid waste applications. We envision a conveyor belt system in which the objects to be monitored (such as Kimwipes* and rubber gloves) are placed on the conveyor belt, which then passes directly through the LRAD sample chamber. In this way, a determination of the contamination level of the object can be made quickly. A fanless waste monitor with this design is now being developed to monitor soil exiting from a soil treatment plant.

\section{CONCLUSIONS}

Airflow LRAD monitors are fully operational and tested. The grid, HV, and filter designs currently used are often excessive. In particular, lower voltages and fan speeds result in generally lower noise. The noise in these detectors is dominated by cosmic-ray and radon contributions, making the electronic noise contribution less important. Sensitivity improvements (such as those offered by the parallel-plate detector geometry) may be more important than overall noise reduction.

\section{REFERENCES}

1. D.W. MacArthur, K.S. Allander, J.A. Bounds, and K.B. Butterfield, "Small Long-Range Alpha Detector (LRAD) with Computer Readout," Los Alamos National Laboratory report LA-12199-MS (October 1991).

2 D.W. MacArthur, "Long-Range Alpha Detector (LRAD) Advanced Concepts," Los Alamos National Laboratory report LA-12225-MS (December 1991).

3. D.W. MacArthur, K.S. Allander, J.A. Bounds, J.L. McAtee, "LRAD-Based Alpha Particle Contamination Monitoring of Personnel and Equipment," Nuclear Technology, 102, 270 (1993).

4. D.W. MacArthur, K.S. Allander, "Long-Range Alpha Detectors," Los Alamos National Laboratory report LA-12073-MS (July 1991).

5. K.S. Allander, J.A. Bounds, M.M. Catlett, D.A. Close, D.W. MacArthur, and J.L. McAtee, "Applications of a Long-Range Alpha Detector (LRAD) for Environmental Restoration," Los Alamos National Laboratory document LA-UR-91-389.

6. D.W. MacArthur, and J.L. McAtee, "Long-Range Alpha Detector (LRAD)," Presented at The American Nuclear Society 1991 winter meeting, Los Alamos National Laboratory document LA-UR-91-3398.

7. D.W. MacArth, K.S. Allander, J.A. Bounds, R.W. Caress, M.M. Catlett, and D.A. Rutherford, "Alpha Contamination Monitoring of Surfaces, Objects, and Enclosed Areas," IEEE Trans. on Nuc. Sci., 40, 840 (1993).

8. J.P. Johnson, K.S. Allander, J.A. Bounds, R.W. Caress, J.D. Johnson, and D.W. MacArthur, "Long-Range Alpha Detection Applied to Mixed-waste Monitoring," Los Alamos National Laboratory document LA-UR-93-904.

9. D.W. MacArthur, K.S. Allander, J.A. Bounds, M.M. Catlett, R.W. Caress, and D.A. Rutherford, "Environmental Alpha Contamination Monitoring with the LRAD," ACS News Service, 1993, Los Alamos National Laboratory document LA-UR-93-453. 
10. R.W. Caress, K.A. Allander, J.A. Bounds, D.W. MacArthur, M.M. Catlett, and D.A. Rutherford, "Long-Range Alpha Detection Applied to Soil Surface Monitoring,"

Conference Record of the 26th Annual Topical Meeting of the Health Physics Society, January 24-28, 1993, Lake Coeur d'Alene, ID.

11. Michelle Catlett, "TA-06 Alpha Monitoring Results," Los Alamos National Laboratory memorandum N2-92:852MMC to C. Rofer (July 1992).

12. D.W. MacArthur, K.S. Allander, J.A. Bounds, R.W. Caress, M.M. Catlett, and D.A. Rutherford, "LRAD Surface Monitors," Los Alamos National Laboratory report LA12524-MS (February 1993). 


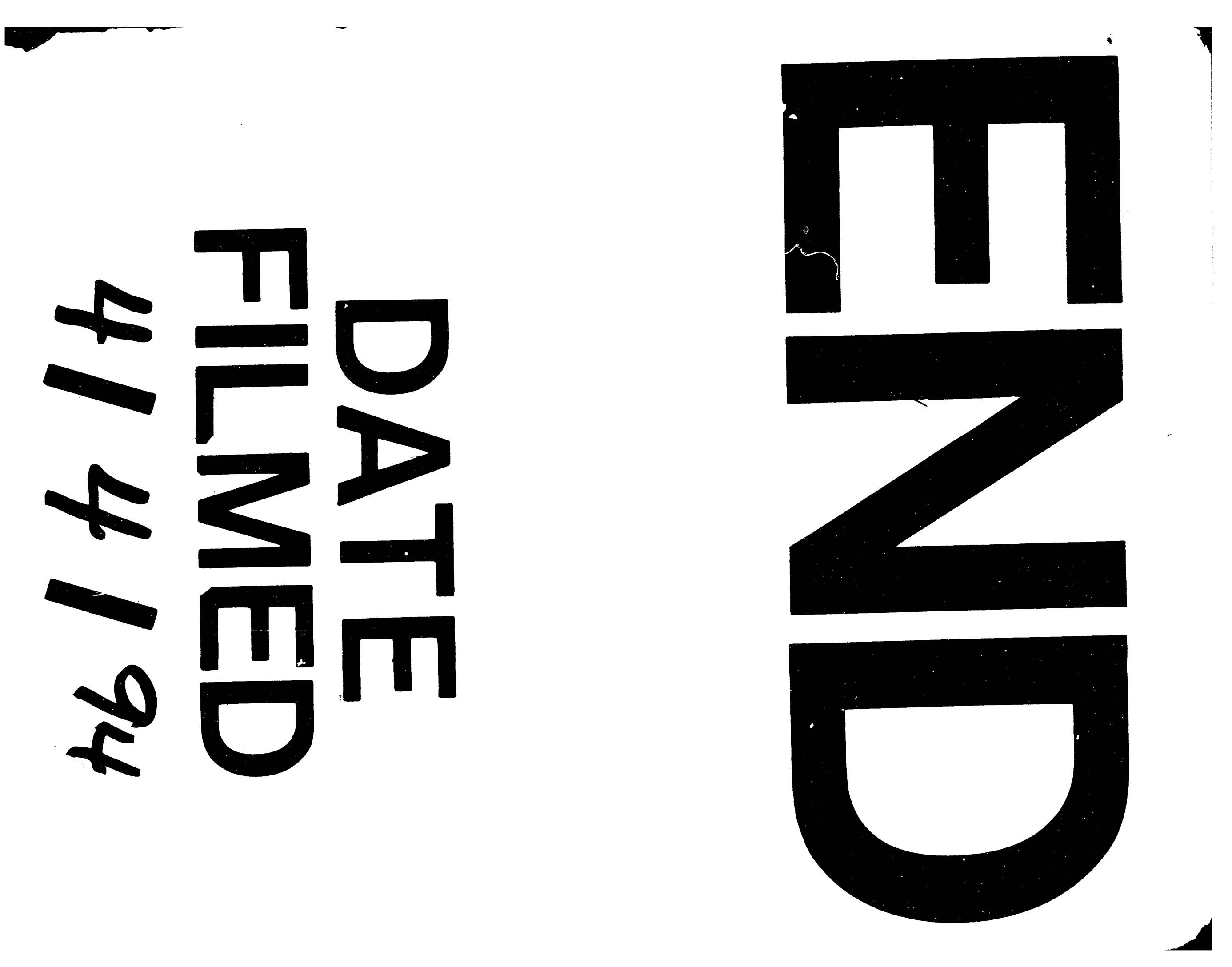


